\title{
TAXONOMIC NOTES ON SIMULIIDAE (DIPTERA) FROM THAILAND: DESCRIPTION OF A NEW SPECIES AND NEW DISTRIBUTIONAL RECORDS OF NINE KNOWN SPECIES
}

\author{
Chaliow KuvangkadiloK ${ }^{1}$ And Hiroyuki TAKaOKA ${ }^{2, *}$ \\ Received April 3, 2000/Accepted June 21, 2000
}

\begin{abstract}
Simulium (Gomphostilbia) chumpornense sp. nov. is described from reared adults, pupae and mature larvae collected from southern Thailand. This new species is assigned to the varicorne species-group within the subgenus Gomphostilbia by having the adult antennae composed of $2+8$ segments in place of usual $2+9$ segments. In addition, nine known simuliid species, most of which were described from Peninsular Malaysia, are recorded for the first time from Thailand, bringing the total number of simuliid species in this country to 40 .
\end{abstract}

Key words: Simuliidae, black fly, Thailand, new species, fauna

Since Takaoka and Suzuki (1984) reported 19 black-fly species (Diptera: Simuliidae) from Thailand, seven more species were added (Takaoka and Saito, 1996; Takaoka and Adler, 1997), totaling the number of simuliid species from this country to 26 consisting of 22 named and four unnamed species.

In 1996-1999, one of us (CK) made faunistic and ecological surveys on Simuliidae in various provinces of Thailand, and collected many species including five new species, nine newly recorded ones, and two unnamed ones (i.e., Simulium sp. A and S. sp. B, sensu Takaoka and Suzuki, 1984). In our recent cytogenetic papers (Kuvangkadilok et al., 1998, 1999a, 1999b), we have applied two Malaysian known species names, i.e., $S$. caudisclerum and S. feuerborni, for S. sp. A and S. sp. B, respectively. In addition, we have already described four of the five new black-fly species, of which three were assigned to the subgenus Simulium s. str. and the one remained unplaced in any subgenera (Takaoka and Kuvangkadilok, 1999).

We herein describe the remaining one new species which apparently belongs to the subgenus Gomphostilbia, and give brief notes on the nine known species which were newly recorded from Thailand.

The morphological features and terms used herein follow mostly those of Crosskey (1969), and partially those of Takaoka (1983). All type specimens of a new species will be deposited in the Department of Biology, Faculty of Science, Mahidol University, Bangkok, Thailand.

\section{DESCRIPTION OF NEW SPECIES}

\section{Simulium (Gomphostilbia) chumpornense Takaoka and Kuvangkadilok sp. nov.}

Female. Body length $1.8 \mathrm{~mm}$. Head. As wide as thorax. Frons (Fig. 1) brownish black, dull, moderately covered with yellowish white, scale-like, recumbent hairs (Fig. 2) (except median longitudinal portion narrowly bare on upper $1 / 2$ ), and with 1 dark hair on upper part of right side; lower narrow juncture to clypeus also fully covered with yellowish white, scale-like, recumbent hairs; frontal ratio 1.5:1.0:1.7; frons-head ratio 1.0:4.0. Fronto-ocular area (Fig. 3) well developed, narrow. Clypeus brownish black, dull, densely covered with yellowish white, scale-like, recumbent hairs interspersed with several dark hairs along each lateral margin. Antenna (Fig. 4) composed of $2+8$ segments, apical flagellar segments compressed dorsoventrally; scape, pedicel, 2nd and 4th flagellar segments entirely yellow, and 1st and 3rd flagellar segments light or medium

1 Department of Biology, Faculty of Science, Mahidol University, Rama VI Road, Bangkok 10400, Thailand

2 Department of Infectious Disease Control, Oita Medical University, Hasama, Oita 879-5593, Japan *: Correspondent author 
brown except base of 1st flagellar segment yellow, and 5th to 8th flagellar segments brownish black. Maxillary palp composed of 5 segments, light brown, proportional lengths of $3 \mathrm{rd}$, 4th and 5th segments 1.0:1.2:2.5, 3rd segment (Fig. 5) widened distally; sensory vesicle (Fig. 5) of moderate size, nearly ellipsoidal, $0.36 \times$ as long as 3rd segment, with medium opening. Maxillary lacinia with 9 inner teeth and 13 or 14 outer teeth. Mandible with 22-24 small inner teeth and lacking outer ones. Cibarium (Fig. 6) with a pair of triangular, well sclerotized projections at posterior margin; any processes or tubercles absent. Thorax. Scutum brownish black with anterolateral calli somewhat paler, subshiny, thinly white pruinose, with 3 dark longitudinal vittae ( 1 medial and 2 submedial), densely covered with yellowish white, scale-like, recumbent hairs, interspersed with dark, similar hairs; scutellum brownish black, covered with short, yellowish white, scale-like hairs as well as long, upright, dark hairs along posterior margin. Postscutellum brownish black, bare. Pleural membrane bare. Katepisternum brownish black, longer than deep, with fine, short, yellowish white hairs. Legs. Foreleg: coxa and trochanter pale yellowish white; femur dark grey; tibia pale yellowish white, with basal knee black, and with subbasal and subapical dark grey bands; tarsus brownish black with basal knee of basitarsus yellow, with sparse dorsal hair crest; basitarsus nearly cylindrical, ca. $5.9 \times$ as long as its greatest width. Midleg: coxa brownish black; trochanter pale yellowish white; femur dark grey with apex paler; tibia pale yellowish white on basal $2 / 5$ with dark grey or light brown subbasal band, and medium brown on distal $3 / 5$; tarsus light to medium brown with basal $2 / 3$ of basitarsus, and base of 2 nd tarsal segment yellowish white. Hind leg (Fig. 7): coxa medium brown, trochanter pale yellowish white; femur light brown with base pale yellowish white and apical cap medium brown; tibia yellowish white on basal $2 / 3$ with dark grey subbasal band, and brownish black on distal $1 / 3$; tibia much angulate posteriorly at distal $1 / 3$ and also at basal $1 / 3$ when viewed laterally; tarsus brownish black except basal $2 / 3$ or a little more of basitarsus, basal $1 / 2$ of 2 nd tarsal segment, and base of 3rd tarsal segment yellowish white; basitarsus narrow, nearly parallel-sided, ca. $6.5 \times$ as long as wide, and ca. $0.50 \times$ and ca. $0.48 \times$ as wide as greatest width of tibia and femur, respectively; calcipala ca. $1.3 \times$ as long as wide, and ca. $0.6 \times$ as wide as distal portion of basitarsus. All femora, tibia and parts of tarsus densely covered with pale or dark, scale-like hairs. Claws (Fig. 8) each with large basal tooth, $0.5 \times$ as long as claw. Wing. Length $1.6 \mathrm{~mm}$. Costa with dark spinules as well as dark hairs except basal hair tuft pale. Subcosta almost bare. Hair tuft on stem vein pale. Basal portion of radius fully haired. Abdomen. Basal scale light brown, with fringe of pale hairs. Abdomen brownish black except base of 2nd segment somewhat paler, sparsely or moderately covered with short yellowish white hairs, intermixed with dark hairs; tergites of segments 2, 6, 7 and 8 shiny; sternal plate on segment 7 undeveloped. Genitalia (Figs. 9 and 10). Sternite 8 bare medially, with 10-12 long hairs and a few short hairs on each side. Anterior gonapophyses nearly triangular, thin, membraneous, covered densely with microsetae (though posteromedial corner somewhat widely bare), interspersed with 2-4 short setae; inner margins narrowly sclerotized, moderately separated from each other. Genital fork of usual inverted-Y form; arms slender, folded medially, forming a distinct projection directed forward. Paraproct somewhat produced ventrally, with 16-18 long hairs on outer surface, and with 3 sensilla on inside surface. Cercus ca. $0.5 \times$ as long as wide, rounded posteriorly. Spermatheca oblong, ca. 1. $8 \times$ as long as wide, well sclerotized, even near tubal juncture, with several internal setae.

Male. Body length probably $2.0 \mathrm{~mm}$. Head. Lost. Thorax. Scutum brownish black, shiny, whitish greypruinose except central large area unpruinose, densely covered with yellow, scale-like, recumbent hairs, interspersed with dark ones. Scutellum brownish black, covered with yellow, scale-like, short hairs and several dark hairs near posterior margin. Postscutellum brownish black, bare. Pleural membrane bare. Katepisternum as in female. Legs. Colorings and shapes as in female except relative sizes as follows: fore basitarsus ca. $6.2 \times$ as long as greatest width; hind basitarsus (Fig. 11) ca. $6.1 \times$ as long as wide, and ca. $0.55 \times$ and ca. $0.51 \times$ as wide as greatest width of tibia and femur, respectively. Calcipala ca. $1.2 \times$ as long as wide. Wing. As in female. Abdomen. Basal scale light brown, with fringe of pale hairs. Dorsal surface of abdomen brownish black except basal $3 / 4$ of 2nd segment yellow to light brown, covered with dark hairs; segments 2, 5, 6 and 7 each with a pair of shiny dorsolateral patches, those on segment 2 silvery iridescent in certain angles of light. Genitalia (Figs. 12-16). Coxite in ventral view, subquadrate, ca. $1.5 \times$ as long as wide. Style ca. $0.85 \times$ as long as coxite, gradually tapered toward apex, curved inward, with apical spine. Ventral plate transverse, densely covered with microsetae on most area of ventral surface and central area of posterior surface; basal arms directed forward, expanded laterally and dorsally near base. 

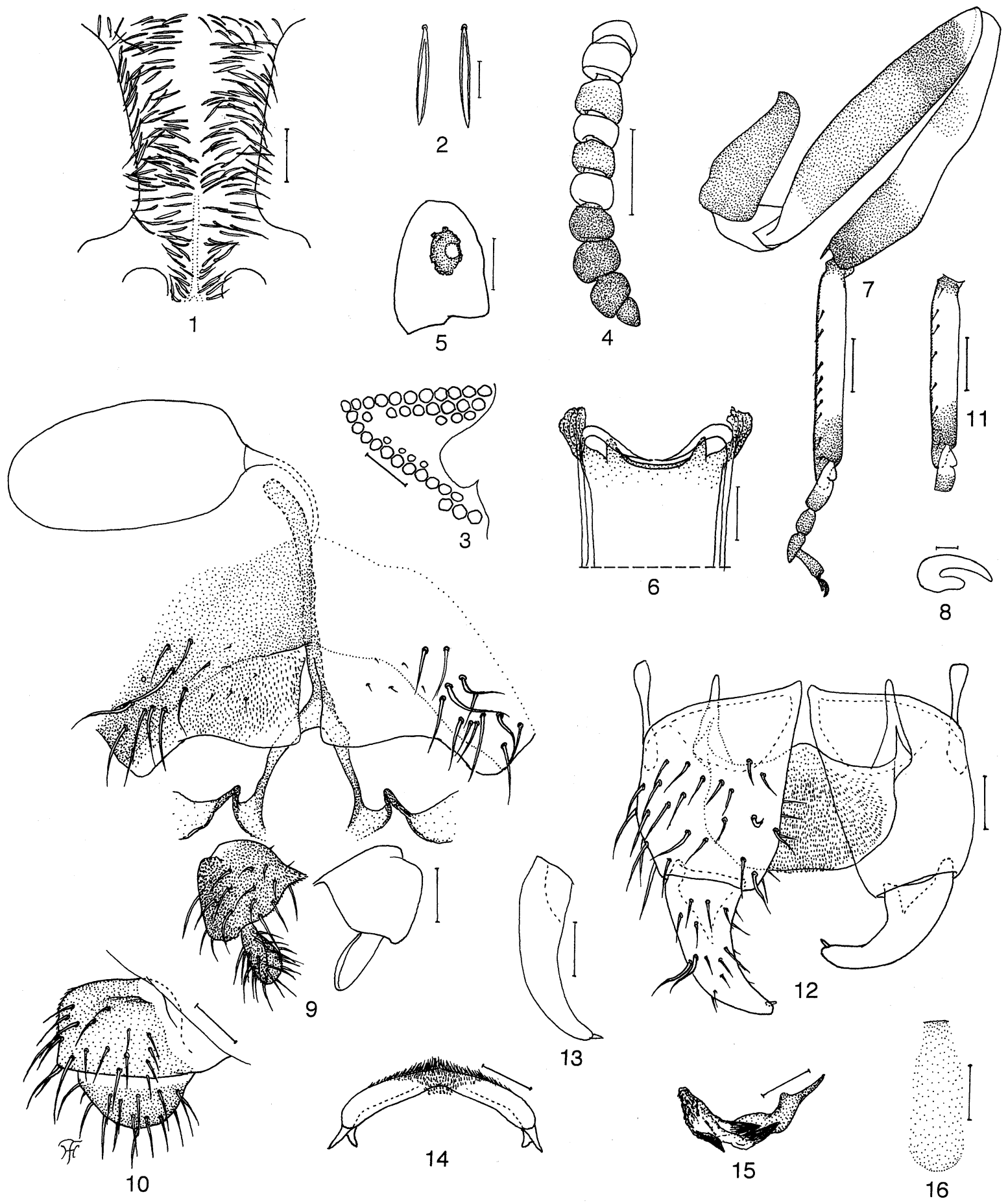

Figures 1-16 Morphological characters of S. chumpornense sp. nov. 1-10, female, and 11-16, male. 1, frons; 2, scale-like hairs on frons; 3, fronto-ocular area; 4, antenna; 5, 3rd segment of maxillary palp with sensory vesicle inside; 6 , cibarium; 7, hind leg; 8, claw of hind leg; 9, genitalia in situ (ventral view), showing 8th sternite, anterior gonapophyses, genital fork, paraprocts, cerci and spermatheca; 10, paraproct and cercus (lateral view); 11, hind basitarsus and 2nd tarsal segment; 12, genitalia in situ (ventral view) showing coxites, styles, and ventral plate; 13, right style (medial view); 14, ventral plate (end view); 15, left paramere (end view); 16, median sclerite (end view). Scale bars; $0.1 \mathrm{~mm}$ for figs. 4, 7 and 11; $0.05 \mathrm{~mm}$ for figs. 1 and 3; $0.03 \mathrm{~mm}$ for figs. 5, 6, 9, 10, 12-16; 0.01 mm for figs. 2 and 8. 


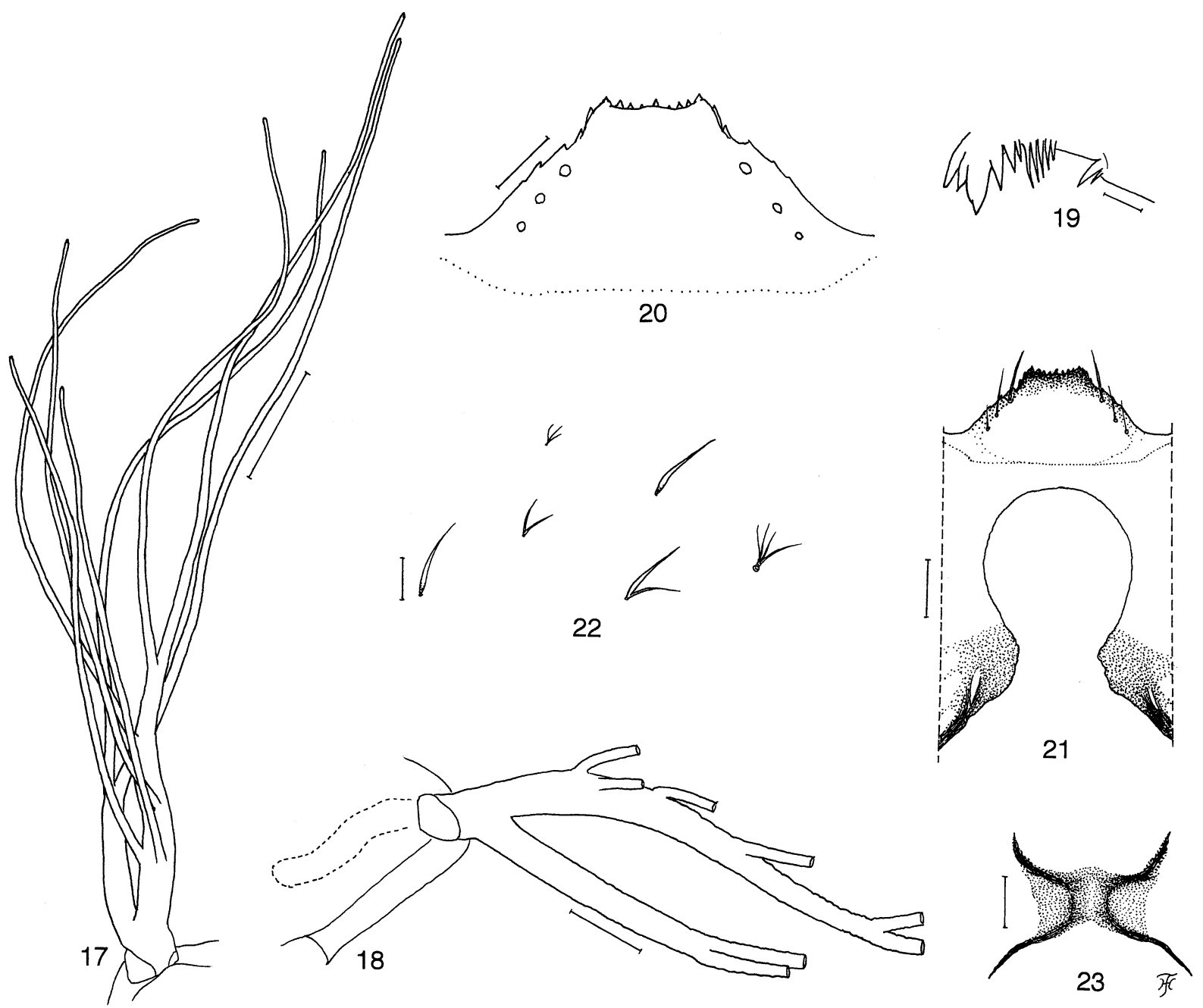

Figures 17-23 Morphological characters of S. chumpornense sp. nov. 17 and 18, pupa, and 19-23, larva. 17, left gill filaments (dorsal view); 18, basal $1 / 3$ of right gill and interspiracular trunk (lateral view) showing an arrangement of filaments; 19, apical portion of mandible; 20, hypostomium (bristles omitted); 21, ventral surface of head capsule showing hypostomium and postgenal cleft; 22 , various setae on dorsal surface of abdomen; 23 , anal sclerite. Scale bars: $0.2 \mathrm{~mm}$ for fig. $17 ; 0.1 \mathrm{~mm}$ for fig. $18 ; 0.05 \mathrm{~mm}$ for figs. 21 and $23 ; 0.03 \mathrm{~mm}$ for fig. $20 ; 0.01 \mathrm{~mm}$ for figs. 19 and 22 .

Parameres of moderate size, each with 3 long hooks and several short incomplete ones. Median sclerite thin, plate-like, wide, with apex rounded. Cerci small, rounded, each with 10 or 11 short hairs.

Pupa. Body length $2.0 \mathrm{~mm}$. Head. Integument yellowish brown, moderately or somewhat sparsely covered with round tubercles; antennal sheath normal, with no spinous projections, and almost bare; face with 1 pair of simple, long trichomes with coiled or uncoiled apex, and frons with 3 pairs of simple, long trichomes with uncoiled apex; 3 frontal trichomes on each side arising close together, subequal in length to one another and also to facial one. Thorax. Integument yellowish brown, moderately covered with round tubercles, with 3 pairs of simple, long trichomes dorsally, with 2 pairs of simple, long trichomes anterolaterally, with 1 pair of simple, medium trichomes posterolaterally, and with 3 pairs of simple, medium trichomes ventrolaterally. Gill (Figs. 17 and 18) composed of 8 slender filaments, with somewhat swollen, transparent organ ventrally at base; gill divided vertically near base into 2 main stout filaments, of which upper one is much thicker than lower one, and with 5 slender filaments each arising independently from its dorsal or outer surface; lower main stout filament further divided into 2 slender filaments, of which outer one is somewhat thinner at least near bifurcation than the inner one; all filaments light yellow- 
ish brown, subequal in length to one another (1.2-1.6 $\mathrm{mm}$ ), slightly tapered toward apical tips; cuticular surface of filaments with distinct annular ridges and furrows gradually becoming indistinct apically, and densely covered with minute tubercles; annular ridges on basal portion of upper and lower main filaments very distinct forming reticulate pattern, with relatively larger tubercles on ridges and smaller ones on interridges. Abdomen. Terga 1 and 2 pale yellow, almost bare; tergum 1 with 1 simple, slender seta on each side; tergum 2 with 1 simple, slender, short seta and 5 short, somewhat spinous setae, submedially on each side; terga 3 and 4 pale, each with 4 hooked spines and 1 short, somewhat spinous seta on each side; tergum 5 lacking spine-combs; terga 6-9 each with distinct spine-combs in transverse row, together with comb-like groups of minute spines on each side; tergum 9 with a pair of distinct, conical terminal hooks, which have round apex. Sternum 4 with 1 simple hook (slightly smaller in size than those on sternum 7) and a few simple, slender, minute setae on each side; sternum 5 with a pair of bifid hooks submedially on each side; sterna 6 and 7 each with a pair of bifid inner and simple or bifid outer hooks somewhat spaced from each other, and a few, simple, short, slender minute setae on each side. Each side of segment 9 with 3 grapnel-like hooklets. Cocoon. Simple, wall-pocketshaped, neatly and compactly woven without open spaces in webs, moderately extending ventrolaterally; anterior margin somewhat thickly woven; posterior $1 / 2$ with floor roughly woven; individual threads indistinct; $2.8 \mathrm{~mm}$ long $\times 1.5-1.8 \mathrm{~mm}$ wide.

Mature larva. Body length $3.8-4.0 \mathrm{~mm}$. Body pale yellowish, with dark greyish transverse band on 1st thoracic segment and on each abdominal segment. Cephalic apotome pale yellow, moderately covered with short colorless setae; head spots indistinct. Antenna with 3 segments (of subequal length) and apical sensillum, longer than stem of labral fan. Labral fan with 2831 main rays. Mandible (Fig. 19) with comb-teeth decreasing in size from 1st to 3rd; mandibular serration consisting of 2 teeth ( 1 large and 1 small); large tooth directed anteroventrally, making an acute angle distally with ventral margin of mandible. Hypostomium (Fig. 20) with an anterior row of 9 teeth, of which median tooth subequal in length to each corner tooth, and longer than 3 intermediate teeth on each side; lateral margin with 1 tooth or 2; hypostomal bristles 3 or 4 in number, slightly diverging posteriorly from lateral margin on each side. Postgenal cleft (Fig. 21) very deep, leaving narrow bridge. Thoracic segment 3 with 2 pairs (dorsal and dorsolateral) of conical protuberances; thoracic cuticle sparsely covered with simple, bifid or trifid setae (similar to those on abdomen) on dorsal surface. Abdominal segments 1-5 each with 2 pairs (dorsal and dorsolateral) of conical protuberances, of which dorsal pair is somewhat more prominent; abdominal cuticle covered dorsally and dorsolaterally with simple, bifid, trifid and quadrifid setae (Fig. 22) sparsely on segments $1-4$, and moderately on segments 5-8; last segment moderately covered with simple and bifid setae on each side of anal sclerite. Rectal gill compound, each of 3 lobes with 8 finger-like secondary lobules. Anal sclerite (Fig. 23) X-shaped, with anterior arms ca. $0.8 \times$ as long as posterior ones. Accessory sclerite absent. Ventral papillae well developed, conical in shape. Posterior circlet with ca. 60 rows of up to 11 hooklets per row.

Type Specimens. Holotype: female, reared from pupa, collected from Ka Po Waterfall (altitude $40 \mathrm{~m}$ ), Chumporn Province, southern Thailand, 4.VI.1999, by C. Kuvangkadilok and C. Boonkemtong. Paratypes: 1 male, reared from pupa, 2 pupae, and 39 larvae, same data as holotype.

ECOLOGICAL Notes. The pupae and larvae of this new species were collected from trailing grasses in a stream, 5-6 m wide, together with S. nobile. The water temperature and acidity of the stream were $26^{\circ} \mathrm{C}$ and $\mathrm{pH} 9.3$, respectively.

Etymology. The species chumpornense refers to the province, Chumporn, where this species was collected.

REMARKS. This new species is assigned to the varicorne species-group within the subgenus Gomphostilbia, defined by Takaoka and Davies (1996), by having the antenna with $2+8$ segments in place of the usual $2+9$ segments.

The pupa of $S$. chumpornense is characterized by the arrangement of the eight gill filaments, as shown in Figs. 17 and 18. All the four known speices of the varicorne species-group, i.e., S. varicorne Edwards from Indonesia and Peninsular Malaysia, S. shogakii Rubtsov from Japan, Korea, and China, S. burtoni Takaoka and Davies, and S. novemarticulatum Takaoka and Davies, both from Peninsular Malaysia, have the ordinary arrangement of eight gill filaments (i.e., $3+3+2$ filaments) (Bentinck, 1955; Takaoka and Davies, 1995; unpublished data). However S. chumpornense seems to be most closely related to $S$. varicorne since the pupal gill of the latter species is first divided into two rather 
stout filaments near its base, as in S. chumpornense.

The adults of $S$. chumpornense are easily separated from $S$. novemarticulatum by the antenna consisting of $2+8$ segments (c.f., $2+7$ segments in the latter). Among the other three related species which have $2+8$ antennal segments, this new species seems to be more closely related to $S$. varicorne than to $S$. burtoni and $S$. shogakii by having the similar flat ventral plate in the male genitalia. The ventral plates of the latter two species are produced ventrally near its posterior margin (Bentinck, 1955; Takaoka and Davies, 1995).

The female of $S$. chumpornense is easily distinguished from $S$. shogakii by having the ellipsoidal sensory vesicle (Fig. 5) \{c.f., globular in the latter according to Bentinck (1955) \}, and from S. burtoni by having the different color pattern of the antenna (Fig. 4). In the antenna of $S$. burtoni, first and second flagellar segments are dark yellow, and third to eighth ones are dark brown, though most of the inside surface of the fourth segment is yellowish (Takaoka and Davies, 1995). The female of $S$. varicorne has not been known as yet.

\section{Notes ON NEWLy ReCORDED SPECIES}

\section{Simulium (Gomphostilbia) angulistylum Takaoka and Davies, 1995 \\ Simulium (Gomphostilbia) angulistylum Takaoka and Davies, 1995: 42-46 (female, male, pupa and larva).}

Specimens Examined. 30 larvae, Haew Suwat Waterfall (altitude $630 \mathrm{~m}$ ), Khao Yai National Park, Nakorn Ratchasima Province, northeastern Thailand, 10.VI.1998, by C. Kuvangkadilok and C. Boonkemtong; 1 female, 2 males and 25 larvae, Huai Yang Waterfall (altitude 75 $\mathrm{m})$, Prachuap Kirikuan Province, central Thailand, 4.VI. 1999, by C. Kuvangkadilok and C. Boonkemtong; 25 larvae, Sa Nangmanora Waterfall (altitude $150 \mathrm{~m}$ ), Sa Nangmanora Forest, Park, Phangnga Province, southern Thailand, 3.VII.1999, by C. Kuvangkadilok and C. Boonkemtong; 1 male, 2 pupae and 78 larvae, Khao Phra Narai Waterfall (altitude $120 \mathrm{~m}$ ), Ranong Province, southern Thailand, 4.VII.1999, by C. Kuvangkadilok and C. Boonkemtong; 1 female, 1 male and 29 larvae, Muang Tuad Waterfall (100 m), Tai Rom Yen National Park, Suratthani Province, southern Thailand, 3.VIII.1999, by C. Kuvangkadilok and C. Boonkemtong; 2 pupae and 23 larvae, Ngao Waterfall (altitude $50 \mathrm{~m}$ ), Ranong Province, southern Thailand, 4.VII.1999, by C. Kuvangkadilok and C. Boonkemtong; 2 pupae, Huai Luang Waterfall (altitude $300 \mathrm{~m}$ ), Phu-Jong Na-Yoy National Park, Ubon Ratchathani Province, northeastern Thailand, 16. XI.1998, by C. Kuvangkadilok and C. Boonkemtong.

ECOlOGiCAL Notes. The larvae and pupae of this species were collected from fallen leaves and/or trailing grasses in several streams of various widths $0.5-5.0 \mathrm{~m}$. The water temperature and acidity of the streams were $24.0-26.5^{\circ} \mathrm{C}$ and $\mathrm{pH} 7.6-9.4$, respectively. This species was collected together with $S$. grossifilum, S. nakhonense, S. nobile, S. parahiyangum, S. quinquestriatum, S. sheilae, S. siamense, and S. tani.

REMARKS. S. angulistylum was originally described from Peninsular Malaysia (Takaoka and Davies, 1995). This species is characterized by the eight short slender pupal gill filaments and the male genitalia with an abruptly-bent style and a posteriorly-attenuated ventral plate. The Thai specimens are in good agreement at all stages with the original descriptions.

\section{Simulium (Gomphostilbia) sheilae Takaoka and Davies, 1995 \\ Simulium (Gomphostilbia) sheilae Takaoka and Davies, 1995: 60-65 (female, male, pupa and larva).}

Specimens ExAmined. 1 male, 4 pupae and 255 larvae, Boripat Waterfall (altitude $50 \mathrm{~m}$ ), Thalay Bun National Park, Songkhla Province, southern Thailand, 1.VI.1999, by C. Kuvangkadilok and C. Boonkemtong; 3 females, 1 male, 6 pupae and 32 larvae, Tone Phrew Waterfall (altitude $125 \mathrm{~m}$ ), Khao Bun Tad Wildlife Sanctuary, Trang Province, southern Thailand, 2.VI.1999, by C. Kuvangkadilok and C. Boonkemtong: 1 male, Huai Yang Waterfall (altitude $75 \mathrm{~m}$ ), Prachuap Kirikuan Province, western Thailand, 4.VI.1999, by C. Kuvangkadilok and C. Boonkemtong.

ECOlOGICAL Notes. The pupae and larvae of this species were collected from fallen leaves and/or small plant roots in several streams $0.5-3.0 \mathrm{~m}$ wide. The water temperature and acidity of the streams were 24$26^{\circ} \mathrm{C}$, and $\mathrm{pH} 7.0-8.4$, respectively. This species was collected together with $S$. fenestratum, S. grossifilum, S. nakhonense and S. tani.

REMARKS. S. sheilae was originally described from Peninsular Malaysia, and was assigned to the ceylonicum species-group by Takaoka and Davies (1995). This species is separated from other related 
species of the same group by the enlarged oblong female sensory vesicle (ca. 0.7 times as long as 3rd maxillary palpal segment) and the almost brown male hind basitarsus (though basal $1 / 3$ or a little less somewhat paler). The reared adult female and male specimens, as well as pupal and larval ones examined in this study, are morphologically almost the same as those originally described.

\section{Simulium (Gomphostilbia) dentistylum Takaoka and Davies, 1995 \\ Simulium (Gomphostilbia) dentistylum Takaoka and Davies, 1995: 51-55 (male, pupa and larva).}

SPECIMENS ExAmined. 1 male reared from pupa, Huai Luang Waterfall (altitude $300 \mathrm{~m}$ ), Phu-Jong Na-Yoy National Park, Ubon Ratchathani Province, northeastern Thailand, 16.XI.1998, by C. Kuvangkadilok and C. Boonkemtong; 1 pupa, Yong Waterfall (altitude $120 \mathrm{~m}$ ), Nakorn Srithammarat Province, southern Thailand, 19. IV.1999, by C. Kuvangkadilok and C. Boonkemtong.

ECOLOGICAL Notes. The pupae of this species were collected from fallen leaves in streams $1.0-5.0 \mathrm{~m}$ wide. The water temperature and acidity of the streams were $24.0-26.0^{\circ} \mathrm{C}$ and $\mathrm{pH} 7.4-7.5$, respectively. This species was collected together with $S$. asakoae, S. chainarongi, $S$. nakhonense, S. nodosum, S. parahiyangum, S. siamense and $S$. tani.

REMARKS. S. dentistylum was originally described from Peninsular Malaysia (Takaoka and Davies, 1995). This species is very similar to $S$. parahiyangum by having the eight short very slender pupal gill filaments on each side, and the very deep larval postgenal cleft, but differs from the latter by the arrangement of the pupal gill, the fewer tubercles on each round ridge of the pupal antennal sheaths, and the absence of the dorsal protuberances on the larval abdomen. The two pupae and one reared adult male from Thailand agree well morphologically with the original descriptions.

\section{Simulium (Gomphostilbia) gombakense Takaoka and Davies, 1995 \\ Simulium (Morops) gombakense Takaoka and Davies, 1995: 82-84 (larva). \\ Simulium (Gomphostilbia) gombakense: Takaoka, 2000: (male and pupa).}

Specimens ExAmined. 18 larvae, Mae Klang Waterfall (altitude $940 \mathrm{~m}$ ), Doi Inthanon National Park, Chiang
Mai Province, northern Thailand, 18.V.1997, by C. Kuvangkadilok, S. Phayuhasena and C. Boonkemtong; 1 female reared from pupa, Riang Thong Waterfall (175 $\mathrm{m}$ in altitude), Khao-Pu Khao-Ya National Park, Pattalung Province, southern Thailand. 2.VI.1999, by C. Kuvangkadilok and C. Boonkemtong.

ECOLOGICAL Notes. The pupa and larvae of this species were collected from fallen leaves in two streams $0.5 \mathrm{~m}$ and 1.0-2.0 $\mathrm{m}$ wide, respectively. The water temperature and acidity were $25.5^{\circ} \mathrm{C}$ and $\mathrm{pH} 8.4$ in one stream, and $26.0^{\circ} \mathrm{C}$ and $\mathrm{pH} 9.4$ in the other. This species was collected together with $S$. asakoae and $S$. tani or with $S$. nakhonense.

REMARKS. This species was originally described from pharate pupal and larval specimens from Peninsular Malaysia and was tentatively assigned to the subgenus Morops (Takaoka and Davies, 1995). However, it was transferred to the subgenus Gomphostilbia when its adult male reared from a pupa was obtained and studied (Takaoka, 2000). The pupa of this species is characterized by its gill of much inflated form with six finger-like projections and with eight slender thread-like filaments (Takaoka, 2000). The pupa and larvae collected from Thailand agree well morphologically with the redescriptions (Takaoka, 2000).

\section{Simulium (Simulium) grossifilum Takaoka and Davies, 1995 \\ Simulium (Simulium) grossifilum Takaoka and Davies, 1995: 105-110 (female, male, pupa and larva).}

Specimens ExAmined. 1 male reared from pupa, and 8 larvae, Muang Tuad Waterfall (100 $\mathrm{m}$ in altitude), Tai Rom Yen National Park, Nakorn Srithammarat Province, southern Thailand, 3.VI.1999, by C. Kuvangkadilok and C. Boonkemtong; 56 larvae, Ngao Waterfall (altitude $50 \mathrm{~m}$ ), Ranong Province, southern Thailand, 4.VIII. 1999, by C. Kuvangkadilok and C. Boonkemtong; 1 female reared from pupa and 1 pupa and 3 larvae, Mae Yai Waterfall (100 $\mathrm{m}$ in altitude), Khao Sok National Park, Suratthani Province, southern Thailand, 2.VIII.1999, by C. Kuvangkadilok and C. Boonkemtong.

ECOLOGICAL Notes. The pupae and larvae of this species were collected from trailing grasses and fallen leaves in streams $0.5-2.0 \mathrm{~m}$ wide. The water temperature and acidity of the streams were $24.8-26.0^{\circ} \mathrm{C}$, and $\mathrm{pH}$ 8.0-8.3, respectively. This species was collected 
together with $S$. angulistylum, S. asakoae, S. decuplum, S. malayense, S. nakhonense, S. parahiyangum, S. quinquestriatum, S. tani and S. yongi.

REMARKS. S. grossifilum was originally described from Peninsular Malaysia, and was assigned to the griseifrons species-group (Takaoka and Davies, 1995). This species is very distinctive among the subgenus Simulium s. str. by its swollen pupal gill filaments covered with minute setae, the female anterior gonapophyses with a dorsal projection, and the male lamellate ventral plate. The female, male, pupal and larval specimens collected from Thailand are morphologically in good agreement with the original descriptions.

\section{Simulium (Simulium) malayense Takaoka and Davies, 1995 \\ Simulium (Simulium) malayense Takaoka and Davies, 1995: 120-123 (female, pupa and larva).}

Specimens ExAmined. 1 male reared from pupa, Mae Yai Waterfall (altitude $100 \mathrm{~m}$ ), Khao Sok National Park, Suratthani Province, southern Thailand, 2.VIII.1999, by C. Kuvangkadilok and C. Boonkemtong.

ECOlOGiCAL Notes. The one pupa of this species was collected from a fallen leaf in a small stream $1 \mathrm{~m}$ wide. This species was collected together with S. grossifilum and S. yongi.

REMARKS. S. malayense was described from female, pupal and larval specimens collected from Peninsular Malaysia, and was assigned to the multistriatum species-group (Takaoka and Davies, 1995). This species is easily separated from the other related species of the same group by its simple wall-pocket-shaped cocoon without anterolateral windows. Morphological characters of the pupa collected from Thailand are almost the same as those in the original description.

\section{Simulium (Simulium) nobile de Meijere, 1907}

Simulium nobile de Meijere, 1907: 206 (male); Edwards, 1934: 115 (female, male, pupa and larva).

Simulium (Simulium) nobile: Crosskey, 1973: 428; Crosskey, 1988: 475; Takaoka and Davies, 1995: 123; Takaoka and Davies, 1996: 61 (female, male, pupa and larva).

Specimens ExAmined. 8 females, 6 males, 60 pupae and ca. 700 larvae, Ka Po Waterfall (altitude $40 \mathrm{~m}$ ),
Chumporn Province, southern Thailand, 5.VII.1999, by C. Kuvangkadilok and C. Boonkemtong; 6 pupae and 114 larvae, Sa Nangmanora Waterfall (altitude $50 \mathrm{~m}$ ), Sa Nangmanora Forest Park, Phangnga Province, southern Thailand, 3.VII.1999, by C. Kuvangkadilok and C. Boonkemtong; 7 females, 5 males, 85 pupae and 833 larvae, Tone Sai Waterfall (altitude $30 \mathrm{~m}$ ), Phuket Province, southern Thailand, 2.VIII.1999, by C. Kuvangkadilok and S. Phayuhasena.

ECOlOGiCAL Notes. The pupae and larvae of this species were collected from fallen leaves in streams 1.0$3.0 \mathrm{~m}$ wide. The water temperature and acidity were $25.0-27.0^{\circ} \mathrm{C}$, and $\mathrm{pH} 7.8-9.4$, respectively. This species was collected together with $S$. angulistylum, S. chumpornense, S. nakhonense and S. siamense.

REMARKS. S. nobile was originally described from Java (de Meijere, 1907), and later recorded from South Sumatra (Edwards, 1934), Peninsular Malaysia and Sabah (Crosskey, 1973). This species is a type species of the nobile species-group, and is readily distinguished, by its six short slender pupal gill filaments, from $S$. nodosum, the only species of the same group so far known from Thailand. The Thai specimens examined in this study are morphologically almost the same as the Javanese specimens redescribed by Takaoka and Davies (1996).

\section{Simulium (Simulium) rudnicki Takaoka and Davies, 1995}

Simulium (Simulium) rudnicki Takaoka and Davies, 1995: 155-157 (female).

Specimens ExAmined. 20 pupae and 216 larvae, Mae Ya Waterfall (altitude $520 \mathrm{~m}$ ), Doi Inthanon National Park, Chiang Mai Province, northern Thailand, 21.VIII.1996, by C. Kuvangkadilok, S. Phayuhasena and C. Boonkemtong: 83 larvae, Vachiratharn Waterfall (altitude 700 m), Doi Inthanon National Park, Chiang Mai Province, northern Thailand, 15.II.1997, by C. Kuvangkadilok, S. Phayuhasena and C. Boonkemtong; 13 larvae, Tad Deuan Waterfall (altitude $170 \mathrm{~m}$ ), Srisatchanalai National Park, Sukothai Province, northern Thailand, 26.I.1999, by C. Kuvangkadilok and C. Boonkemtong.

ECOlOGical Notes. The pupae and larvae of this species were collected from rock and stone surfaces in streams 1.0-2.0 m wide. The water temperature and acidity of the streams were $16-22^{\circ} \mathrm{C}$ and $\mathrm{pH} 8.4-9.0$, 
respectively. This species was collected together with $S$. nakhonense, S. quinquestriatum and S. siamense.

REMARKS. S. rudnicki was originally described only from two females collected from Langkawi Island, Malaysia, and remained ungrouped within Simulium s. str. (Takaoka and Davies, 1995). Two pharate females dissected out of the pupae collected from Thailand conform to the original description in most characters including the yellowish leg colorings and the anterior gonapophyses with a narrow transparent portion along inner and posterior margins. The pupae collected from Thailand are not different from those of S. rudnicki recently collected from Langkawi Island (unpublished data). They have six slender gill filaments on each side.

\section{Simulium (Simulium) yongi Takaoka and Davies, 1997}

Simulium (Simulium) yongi Takaoka and Davies, 1997: 11-16 (female, male, pupa and larva).

Specimens ExAmined. 1 female reared from pupa, Mae Yai Waterfall (altitude $100 \mathrm{~m}$ ), Khao Sok National Park, Suratthani Province, southern Thailand, 2.VIII.1999, by C. Kuvangkadilok and S. Phayuhasena.

ECOLOGICAL Notes. The only one pupa of this species was collected from a fallen leaf in a small stream ca. 1.0 $m$ wide. This species was collected together with $S$. grossifilum and $S$. malayense.

REMARKS. The reared female and its pupal exuvia examined in this study agree well morphologically with those originally described from Peninsular Malaysia by Takaoka and Davies (1997). The female of this species is very similar to $S$. rudnicki, but differs from the latter by the darker leg colorings.

\section{ACKNOWLEDGEMENTS}

This work was supported by the TRF/BIOTEC Special Program for Biodiversity Research and Training grant BRT 139007 to CK, and in part by the Grant-in Aid of Ministry of Education, Science and Culture, Japan (no. 11670246) to HT.

\section{REFERENCES}

1) Bentinck, W. (1955): The black flies of Japan and Korea (Diptera: Simuliidae), 22 p., 406 Medical General Laboratory U.S. Army, Tokyo.
2 ) Crosskey, R.W. (1969): A re-classification of the Simuliidae (Diptera) of Africa and its islands. Bull. Br. Mus. (Natur. Hist.) (Entomol.) Suppl. 14, 1-195

3 ) Crosskey, R.W. (1973): Family Simuliidae, p. 423-30. In: Delfinado, M.D. and Hardy, D.E., eds., A catalog of the Diptera of the Oriental Region. Vol. I. Suborder Nematocera. University Press of Hawaii, $618 \mathrm{p}$.

4 ) De Meijere, J.C.H. (1907): Studien über Südostasiatische Dipteren I. Tijdschr. Ent., 50, 196-264 (Simuliidae pp. 206-7).

5 ) Edwards, F.W. (1934): Deutsche Limnologische SundaExpedition. The Simuliidae (Diptera) of Java and Sumatra. Arch. Hydrobiol., 13 (Suppl. 5), 92-138

6 ) Kuvangkadilok, C., Boonkemtong, C. and Phayuhasena, S. (1998): C-banding in polytene chromosomes of six Simulium species (Diptera: Simuliidae) from Doi Inthanon National Park, northern Thailand. J. Sci. Soc. Thailand, 24, 215-230

7 ) Kuvangkadilok, C., Phayuhasena, S. and Baimai, V. (1999a): Population cytogenetic studies on Simulium feuerborni Edwards (Diptera: Simuliidae) from northern Thailand. Genome, 42, 80-86

8 ) Kuvangkadilok, C., Phayuhasena, S. and Boonkemtong, C. (1999b): Larval polytene chromosomes of five species of blackflies (Diptera: Simuliidae) from Doi Inthanon National Park, northern Thailand. Cytologia, 64, 197-207

9 ) Takaoka, H. (1983): The blackflies (Diptera: Simuliidae) of the Philippines. xi+199 p., Japan Society for the Promotion of Science, Tokyo

10) Takaoka, H. (2000): Taxonomic notes on Simulium gombakense (Diptera: Simuliidae) from Peninsular Malaysia: descriptions of male and pupa, and subgeneric transfer from Morops to Gomphostilbia. Jpn. J. Trop. Med. Hyg., 28, 111-114

11) Takaoka, H. and Adler, P.H. (1997): A new subgenus, Simulium (Daviesellum), and a new species, S. (D.) courtneyi, (Diptera: Simuliidae) from Thailand and Peninsular Malaysia. Jpn. J. Trop. Med. Hyg., 25, 17-27

12) Takaoka, H. and Davies, D.M. (1995): The Black Flies (Diptera: Simuliidae) of West Malaysia. viii +175 p., Kyushu University Press, Fukuoka

13) Takaoka, H. and Davies, D.M. (1996): The Black Flies (Diptera: Simuliidae) of Java, Indonesia. viii +81 p., Bishop Museum Bull. Entomol. 6., Honolulu

14) Takaoka, H. and Davies, D.M. (1997): Simulium (Simulium) yongi sp. nov. (Diptera: Simuliidae) from Peninsular Malaysia. Jpn. J. Trop. Med. Hyg., 25, 11-16

15) Takaoka, H. and Kuvangkadilok, C. (1999): Four new species of black flies (Diptera: Simuliidae) from Thailand. Jpn. J. Trop. Med. Hyg., 27, 497-509

16) Takaoka, H. and Saito, K. (1996): A new species and new records of black flies (Diptera: Simuliidae) from Thailand. Jpn. J. Trop. Med. Hyg., 24, 163-169

17) Takaoka, H. and Suzuki, H. (1984): The blackflies (Diptera: Simuliidae) from Thailand. Jpn. J. Sanit. Zool., 35, 7-45 